\title{
Application of low-field nuclear magnetic resonance and proton magnetic resonance imaging in evaluation of 'Jinxiu' yellow peach's storage suitability
}

\author{
Hui-juan ZHOU1,2, Zheng-wen YE ${ }^{1 *}$, Zhi-fang YU², Ming-shen SU1, Ji-hong DU1 \\ ${ }^{1}$ Key Laboratory of Protected Horticultural Technology, Forestry and Fruit Research Institute, Shanghai Academy of Agricultural Sciences, \\ Shanghai 201403, P.R.China, ${ }^{2}$ Department of Food Science and Technology, Nanjing Agricultural University, Nanjing 210095, P.R.China
}

\section{A B S T R A C T}

\begin{abstract}
In this study, changes in the transverse relaxation time $\left(T_{2}\right)$, signal intensity $\left(A_{2}\right)$, and images of 'Jinxiu' yellow peach fruits were investigated using low-field nuclear magnetic resonance (LF-NMR) and proton magnetic resonance imaging ( ${ }^{1} \mathrm{H}$-MRI). The water content, (determined using centrifuging technology), fruit firmness, and ethylene production were evaluated at $4 \pm 1{ }^{\circ} \mathrm{C}$ and $25 \pm 2^{\circ} \mathrm{C}$. The results showed a signal peak $\left(\mathrm{A}_{2}\right)$ and $\mathrm{T}_{2}$ at 500-1000 ms. On days 4-6, $\mathrm{T}_{2}$ changed from $796 \mathrm{~ms}$ to $861 \mathrm{~ms}$, and decreased with longer time at $25^{\circ} \mathrm{C}$. Water content also decreased and high adjusted determination coefficient (adj- $\left.R^{2}\right)$ values with water content were found for $\mathrm{T}_{2}\left(R^{2}=0.95\right)$ and $\mathrm{A}_{2}\left(R^{2}=0.99\right)$, indicating a high degree of fit for the prediction equations. $\mathrm{A}_{2}$ decreased and $\mathrm{T}_{2}$ shortened after prolonged storage at $4^{\circ} \mathrm{C}$ and high adj- $R^{2}$ values were found between the water content and $\mathrm{T}_{2}\left(R^{2}=0.93\right)$ and $\mathrm{A}_{2}\left(R^{2}=0.97\right)$. Ethylene production and firmness were the same as for $\mathrm{T}_{2}, \mathrm{~A}_{2}$, and internal breakdown at $25^{\circ} \mathrm{C}$ for $4-6$ days, and $4{ }^{\circ} \mathrm{C}$ for $16-21$ days. Compared with storage at $25^{\circ} \mathrm{C}$, low temperature storage inhibited water loss and also prohibited internal breakdown. $T_{2}$ and $A_{2}$ can be used to evaluate the storage characteristics of yellow peach fruits, and the internal breakdown of pulp tissue could be clearly observed by ${ }^{1} \mathrm{H}-\mathrm{MRI}$, which is a function of LF-NMR. ${ }^{1} \mathrm{H}-\mathrm{MRI}$ can provide high-resolution images showing the internal structure of intact peaches. Thus, LF-NMR is a new technology that could be an effective and simpler method for monitoring and predicting water content, as well as detecting quality issues during peaches storage.
\end{abstract}

Keywords: Low-field nuclear magnetic resonance; Proton magnetic resonance imaging; Yellow peach fruit; Transverse relaxation time; Signal intensity

\section{INTRODUCTION}

'Jinxiu' yellow peach (Prunus persica L. Baihua $\times$ Yunshu1) is a yellow flesh peach cultivar, which due to its excellent sensory properties, such as golden flesh color and sweet, attractive fragrance, and its high economic value, has become a major cultivar in the Yangtze River Delta.

However, the peaches ripen in summer at high temperatures and humidity in southern China, and are susceptible to water loss, breakdown, and decay during storage. Water content is an important indicator of fruit quality and, along with fruit firmness, is related to respiration and ethylene production. Current conventional techniques for water content determination in fruits include sensory, centrifugal, and oven-drying methods. However, some of them are uncertainty, cumbersome or require skilled personnel. Therefore, a simple and convenient method, as well as a non-destructive technique is needed for the determination of water content in fruits.

Nuclear magnetic resonance (NMR) had been successfully applied to quantify the changes in water distribution and mobility during the conversion of muscle to meat, aging, freezing, and cooking (Siciliano et al., 2013; Reid et al., 2006; Bertram et al., 2002). This technique had become an alternative method not only for the conventional determination of water-holding capability (Ruiz-cabrera et al., 2004; Farag et al., 2009), but also for detecting maturity, internal bruising, infection, or chilling injury in horticultural products (Hill and Clark, 2003; Butz et al., 2005; Chayaprasert and Stroshine, 2005), as well as for

\footnotetext{
*Corresponding author:

Zheng-wen YE, Key Laboratory of Protected Horticultural Technology, Forestry and Fruit Research Institute, Shanghai Academy of Agricultural Sciences, Shanghai 201403, P.R.China. E-mail: yezhengwen1300@163.com
} 
evaluating the quality of fruits and vegetables during processing (Marigheto et al., 2004; Mortensen et al., 2005; Gonzalez et al., 2010; Shao and Li, 2013).

Low-field nuclear magnetic resonance (LF-NMR) had been widely applied to analyze the characterization of water mobility and distribution in food (Agudelo et al., 2014; Ogasa., 2016; Haiduc and Duynhoven, 2005) or medical detection in humans (Bakalova et al., 2016), which was a passive and analytical technique of research support system for us. Compared to drying or solvent extraction method, it was also a fast and accurate technology for determining the content of fat and water content (Sorland et al., 2004). Borompichaichartkul et al reported the magnetic resonance imaging (MRI) technology first, which could format images by NMR.(Borompichaichartkul et al., 2005). Alternative applications of MRI based on the principles of NMR could be used for the nondestructive evaluation of important quality attributes in food and agricultural products (Gambhir et al., 2004).

Proton magnetic resonance imaging $\left({ }^{1} \mathrm{H}-\mathrm{MRI}\right)$ technology could stimulate absorbing radio frequency (RF) energy ability because there were a abundant of proton-containing species in fruits and vegetables (Krishna et al., 2015) (Xiao and Wang, 2004). It not only could provide high resolution images for internal structure with different thickness of intact fruits and vegetables which was non-invasive, but also could detect internal demage such as bruises, deacy, water loss, wooliness and voids in apple (Krishna et al., 2015) (Xiao and Wang, 2004), citrus (Gambhir et al., 2004), tomato (Sequi et al., 2007) and pear (Hernandz et al., 2007)fruits, as well as for evaluating the quality of fruits and vegetables during processing (Gonzalez et al., 2010; Shao and Li, 2013), which revealed the senescence process of fruits.

LF-NMR and 1H-MRI technologies had rarely been combined with other physiological indices to study the storage characteristics of fruits and vegetables. In the present research, these technologies were used to investigate changes in water distribution, water loss, and internal breakdown of the pulp tissue of yellow peach fruits during storage. We also evaluated the water content, firmness, and ethylene production to assess the storage time in terms of food safety. Pearson's correlation analysis was performed to explore the use of LF-NMR and potential correlations between transverse relaxation time $\left(T_{2}\right)$, signal intensity $\left(A_{2}\right)$, and water content determination by centrifugation.

\section{MATERIALS AND METHODS}

\section{Plant materials}

All experiments were carried out in 2013-2014. A total of 600 'Jinxiu' yellow peaches were harvested from the experimental orchard of the SAAS in Shanghai. Uniform, unblemished, without mechanical damaging fruit samples of similar size (175-200 g) and background skin color (milky to red) were randomly divided into six groups of 100 fruits per treatment in each group. The fruit was then packed with bubble nets into plastic crates, and were immediately moved to the analysis lab within $30 \mathrm{~min}$ and placed at $20^{\circ} \mathrm{C}$ for $2 \mathrm{~h}$. The initial quality indices were then evaluated, including $\mathrm{T}_{2}, \mathrm{~A}_{2}$, water content, firmness, and ethylene production.

\section{Experimental design}

One group was stored at $25 \pm 2^{\circ} \mathrm{C}$ and $75 \%-80 \%$ humidity, and the other was at $4 \pm 1{ }^{\circ} \mathrm{C}$ and $85 \%-90 \%$ humidity. Each group were further subdivided randomly into five sample groups. Fruit stored at room and low temperatures were randomly selected to determine $A_{2}, T_{2}$, firmness, ethylene production, and to obtain images. Samples from the room temperature group were selected randomly for the determination of firmness, ethylene production, $\mathrm{A}_{2}$ and $\mathrm{T}_{2}$, and to obtain images every day for the 6 days. Samples from the low temperature group were selected randomly for the determination of $\mathrm{A}_{2}$ and $\mathrm{T}_{2}$, and to obtain images every 2 days for the first six measurements, and every 5 days for the last two measurements, while the firmness and respiratory rate were determined every 7 days up to 35 days.

The experimental data from 2013 and 2014 were similar; thus, only the data from 2014 were used for further analysis.

\section{Measurements}

LF-NMR measurements were performed on a $12.797 \mathrm{MHz}$ Macro MR12-100H-I (Niumag Co. Ltd., Shanghai, China). Ten fruits from the room and low temperature groups were randomly selected and placed into $100 \mathrm{~mm}$ NMR glass tubes. Then, the tubes were inserted into the NMR probe. $\mathrm{T}_{2}$ was measured using a Carr-Purcell-Meiboom-Gill sequence. The $T_{2}$ measurements were performed with a $\tau$-value of $335 \mu \mathrm{s}$ (between $90^{\circ}$ and $180^{\circ}$ pulse). Data from 15,000 echoes were acquired over eight scan repetitions. The repetition time between two successive scans was $10 \mathrm{~s}$. Relaxation measurements were performed at $32^{\circ} \mathrm{C}$. MultiExp Inv Analysis software (Niumag) was employed for data analysis using distributed exponential curve fitting. In the time domain, spin-spin relaxation data were presumed to be the sum of the exponentials:

$$
\operatorname{Rmag}(t)=\sum_{j=1}^{n} p 2 j \exp \left(\frac{-t}{t 2 j}\right)+e(t)
$$

where Rmag is the function of the acquisition time $t, P_{2 j}$ and $T_{2 j}$ are the transverse relaxation amplitude and time; and $e$ is the residual error. The relaxation time $T_{2 j}$ and its 
corresponding water content (signal area ratio) $P_{2 j}$ (same as $A_{2,}$ ) were recorded.

Yellow peach fruit pulp $(\sim 10 \mathrm{~g})$ from ten fruits was placed into a centrifuge tube and centrifuged for $10 \mathrm{~min}$ at $10,000 \times g$; the water content was then determined by calculating the difference in weight between the sample before and after the supernatant was removed, and is expressed on wet weight basis (\%).

${ }^{1} \mathrm{H}$-MRI technology was used to obtain images of fruits by cutting them into six layers. Each layer was $15 \mathrm{~mm}$ thick, and an MR12-100H-I $3 \mathrm{~mm}$ probe (Niumag Co. Ltd) was used (repetition time $=2000 \mathrm{~ms}$, echo time $=20 \mathrm{~ms}$, with four replicates, image size $=256 \mathrm{~mm} \times 192 \mathrm{~mm}$ ).

The texture of the fruit flesh was measured using a FTAXT Plus texture analyser (Stable Micro-Systems; Texture Technologies Corp., Scarsdale, NY, USA) fitted with an $8 \mathrm{~mm}$ diameter probe. Firmness tests were conducted on 10 fruit with a pre-test probe speed of $1 \mathrm{~mm} \mathrm{~s}^{-1}$, a test speed of $2 \mathrm{~mm} \mathrm{~s}^{-1}$, and a distance of $5 \mathrm{~mm}$; the firmness values are expressed in $\mathrm{N}$. The same 10 fruit used for the LF-NMR and ${ }^{1} \mathrm{H}-\mathrm{MRI}$ were used in the firmness tests.

Ethylene production was assessed on samples taken from the headspace of sealed 5 L glass jars containing 10 fruit each for $3 \mathrm{~h}$, in triplicate; $5 \mathrm{~mL}$ gas samples were withdrawn from the jars with a syringe through a rubber septum and injected into the GC using a Agilent 7890A gas chromatograph (Agilent Co. Ltd., Palo Alto, California, USA), which was fitted with an 80/100 mesh Porapak Q column and a flame ionization detector. The temperatures of the oven in the GC, injector, and hydrogen flame detector were $70^{\circ} \mathrm{C}$, $150^{\circ} \mathrm{C}$, and $250^{\circ} \mathrm{C}$, respectively. Nitrogen at $0.55 \mathrm{~mL} \mathrm{~s}^{-1}$ was used as the carrier gas at a flow rate of $0.7 \mathrm{~mL} \mathrm{~s}^{-1}$, and hydrogen at $0.55 \mathrm{~mL} \mathrm{~s}^{-1}$ and air at $6.67 \mathrm{~mL} \mathrm{~s}^{-1}$. The ethylene production is expressed in $\mu \mathrm{L} \cdot \mathrm{kg}^{-1} \cdot \mathrm{h}^{-1}$.

\section{Statistical analyses}

Principal component analysis (PCA) was performed with Simca-P+ software (Umetrics AB, Umeå, Sweden). PCA was performed on the $T_{2}$ and $A_{2}$ data to identify cluster patterns. Additional statistical analyses were performed with SPSS version 17 for Windows (SPSS, Inc., Chicago, IL, USA). Linear regression analysis was performed with Origin 8.1 (Original Lab, Co. Ltd., Northampton, Massachusetts, USA). Adjusted determination coefficients $\left(\operatorname{adj}-R^{2}\right)$ were used to evaluate the goodness of fit, and were defined as follows:

$$
\operatorname{adj}-R^{2}=1-\frac{(n-1)\left(1-R^{2}\right)}{n-m}
$$

Where $R^{2}$ is the original determination coefficient, and $n$ and $m$ are the numbers of samples and variables, respectively. The significance levels were set at $p \leq 0.05$.

All data were expressed as the mean $\pm \mathrm{SD}$. The treatments were compared using Duncan's new multiple range test after analysis of variance. The significance levels were set at $p \leq 0.05$.

\section{RESULTS}

\section{Changes in relaxation time and water distribution at} room temperature

$T_{2}$ and $A_{2}$

$\mathrm{T}_{2}$ reflects the level of internal hydrogen protons in the samples, which is related to the binding force and degrees of freedom. Constraints of hydrogen protons are inseparable with the internal structure of the samples. The more hydrogen protons are bound or the smaller the degrees of freedom, the shorter the $\mathrm{T}_{2}$, with the peak position appearing on the left of the $\mathrm{T}_{2}$ spectrum. In contrary, the peak position shifts to the right when $\mathrm{T}_{2}$ lengthens. Only one peak is shown in Fig. 1. The $\mathrm{T}_{2}$ of yellow peach fruits

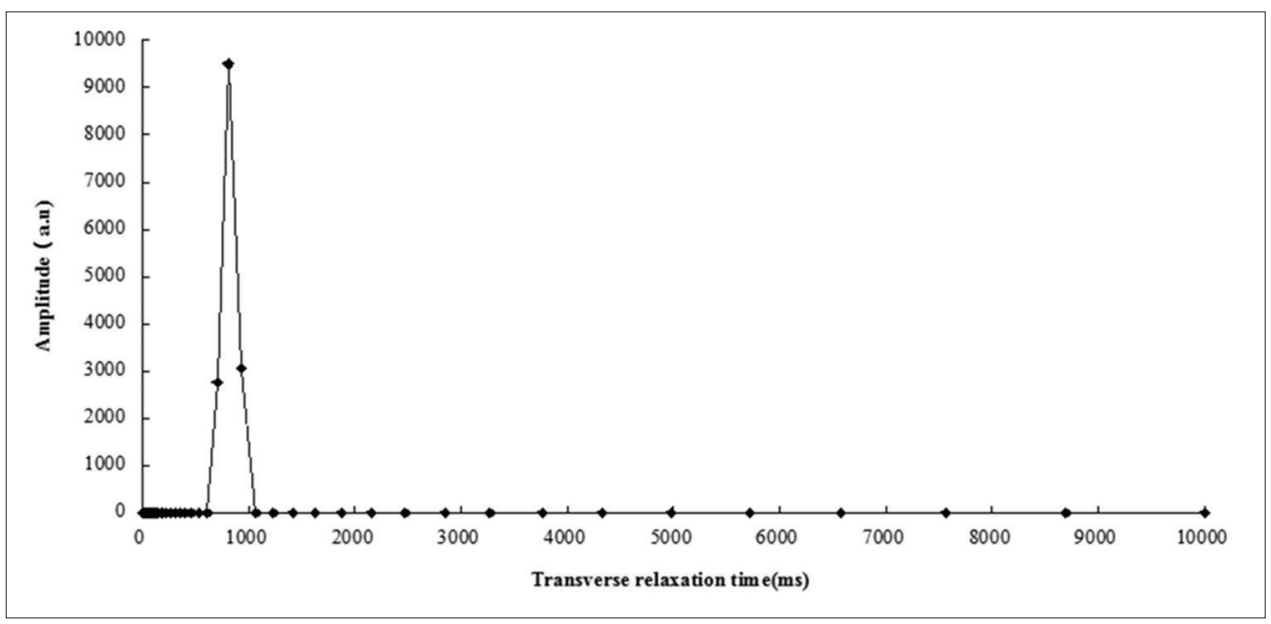

Fig 1. $T_{2}$ and $A_{2}$ of yellow peach fruits. Amplitude: Free water content (a.u.: Arbitrary unit); transverse relaxation time: $T_{2}(m s)$. 
was 500-1000 ms, which shows unrestricted flow of free water in the fruit capillaries. The corresponding peak area describes $A_{2}$.

\section{Relationship between water content and LF-NMR at $25^{\circ} \mathrm{C}$}

Water content is an important indicator of fruit quality. Centrifugation technology can remove water through physical pressure without any chemical reactions between the water and macromolecules, and is often used to evaluate the water content of fruit; however, it is a tedious and invasive method. $T_{2}$ and $A_{2}$ from LF-NMR and water content determination using centrifuging technology were compared. During days $0-4, \mathrm{~T}_{2}$ did not change significantly. On days 4-6, $\mathrm{T}_{2}$ increased from $796 \mathrm{~ms}$ to $861 \mathrm{~ms}$ (Table 1 and Fig. 2). The strength of $\mathrm{A}_{2}$ decreased over storage time (Table 1 and Fig. 2). Over days 1-6, the free water content decreased from 15,544 g to 14,443 g. At day 4, it decreased due to fruit quality degradation and senescence. The water content as assessed using centrifugation technology also decreased on day 3.

Pearson's correlation analysis was carried out using simple linear equations to assess any potential correlations between the means of $\mathrm{T}_{2}$ and $\mathrm{A}_{2}$ from LF-NMR and water content determination using centrifugation in yellow peaches. High adj- $R^{2}$ values of $T_{2}\left(R^{2}=0.95\right)$ and $A_{2}\left(R^{2}=0.99\right)$ with the water content indicated a good fit of the prediction equations. LF-NMR is a novel technology that could be effective for monitoring and predicting the water content of peaches during storage, and could replace centrifugation.

\section{Relationship between water content and LF-NMR at $4^{\circ} \mathrm{C}$}

During $0-5$ days of storage, $\mathrm{T}_{2}$ did not vary significantly (Table 2 and Fig. 3). On days 5-11, both $\mathrm{T}_{2}$ and water mobility declined significantly, with a dramatic drop in these variables from days 11-21 (Table 2). The strength of $\mathrm{A}_{2}$ decreased with the storage time, suggesting a reduction in the free water content. Similar findings were observed when the water content was measured using centrifugation.

High adj- $R^{2}$ values for $T_{2}\left(R^{2}=0.93\right)$ and $A_{2}\left(R^{2}=0.97\right)$ were found with the water content, indicating a high degree of fit with the prediction equations, thus emphasizing the fact that LF-NMR could be an effective method for monitoring and predicting the water content of peaches during low

Table 1: Changes in $T_{2}, A_{2}$, and water content after room temperature storage of peaches

\begin{tabular}{lccc}
\hline $\begin{array}{l}\text { Storage } \\
\text { time (d) }\end{array}$ & $\mathbf{A}_{2}\left(\mathbf{g}^{-1}\right)$ & $\mathbf{T}_{2}(\mathbf{m s})$ & $\begin{array}{c}\text { Water } \\
\text { content (\%) }\end{array}$ \\
\hline 1 & $15544.59 \pm 538.01 \mathrm{a}$ & $810.00 \pm 25.14 \mathrm{~b}$ & $87.66 \pm 2.25 \mathrm{a}$ \\
2 & $15489.70 \pm 701.83 \mathrm{a}$ & $811.94 \pm 34.54 \mathrm{~b}$ & $87.78 \pm 0.94 \mathrm{a}$ \\
3 & $15257.70 \pm 703.65 \mathrm{a}$ & $807.31 \pm 29.30 \mathrm{~b}$ & $85.9 \pm 0.68 \mathrm{ab}$ \\
4 & $14748.51 \pm 695.70 \mathrm{~b}$ & $795.65 \pm 55.27 \mathrm{~b}$ & $83.65 \pm 0.60 \mathrm{~b}$ \\
6 & $14443.75 \pm 685.33 \mathrm{~b}$ & $861.41 \pm 59.15 \mathrm{a}$ & $81.33 \pm 0.76 \mathrm{~b}$ \\
\hline
\end{tabular}

"Mean values $(n=30 ; \pm S D)$ in each column followed by different lower case letters are significantly different at $p \leq 0.05$ as shown by Duncan's new multiple range test, $A_{2}$ : Free water content $\left(\mathrm{g}^{-1}\right) ; \mathrm{T}_{2}$ : Transverse relaxation time (ms)

Table 2: Changes in $T_{2}, A_{2}$ and water content after low temperature storage of peaches

\begin{tabular}{lccc}
\hline $\begin{array}{l}\text { Storage } \\
\text { time }(\mathbf{d})\end{array}$ & $\mathbf{A}_{2}\left(\mathbf{g}^{-1}\right)$ & $\mathrm{T}_{2}(\mathbf{m s})$ & $\begin{array}{c}\text { Water } \\
\text { content }(\%)\end{array}$ \\
\hline 1 & $15641.96 \pm 535.31 \mathrm{a}$ & $825.63 \pm 41.51 \mathrm{a}$ & $87.66 \pm 2.25 \mathrm{a}$ \\
3 & $15583.90 \pm 533.98 \mathrm{a}$ & $808.64 \pm 39.38 \mathrm{a}$ & $88.84 \pm 1.89 \mathrm{a}$ \\
5 & $15663.22 \pm 393.83 \mathrm{a}$ & $829.68 \pm 39.41 \mathrm{a}$ & $89.38 \pm 2.12 \mathrm{a}$ \\
7 & $15162.42 \pm 459.95 \mathrm{a}$ & $765.59 \pm 6.94 \mathrm{~b}$ & $85.38 \pm 1.53 \mathrm{ab}$ \\
9 & $14781.66 \pm 594.06 \mathrm{c}$ & $740.17 \pm 47.20 \mathrm{~b}$ & $83.28 \pm 1.54 \mathrm{~b}$ \\
11 & $14374.28 \pm 600.48 \mathrm{c}$ & $732.90 \pm 41.64 \mathrm{~b}$ & $79.09 \pm 1.91 \mathrm{~b}$ \\
16 & $13656.05 \pm 784.61 \mathrm{~d}$ & $682.51 \pm 45.05 \mathrm{c}$ & $75.14 \pm 1.90 \mathrm{c}$ \\
21 & $12519.31 \pm 880.20 \mathrm{e}$ & $558.61 \pm 38.93 \mathrm{~d}$ & $70.55 \pm 2.49 \mathrm{~d}$ \\
\hline
\end{tabular}

"Mean values $(n=30 ; \pm S D)$ in each column followed by different lower case letters are significantly different at $p \leq 0.05$ as shown by Duncan's new multiple range test, $A_{2}$ : Free water content $(\mathrm{g}-1) ; \mathrm{T}_{2}:$ Transverse relaxation time (ms).

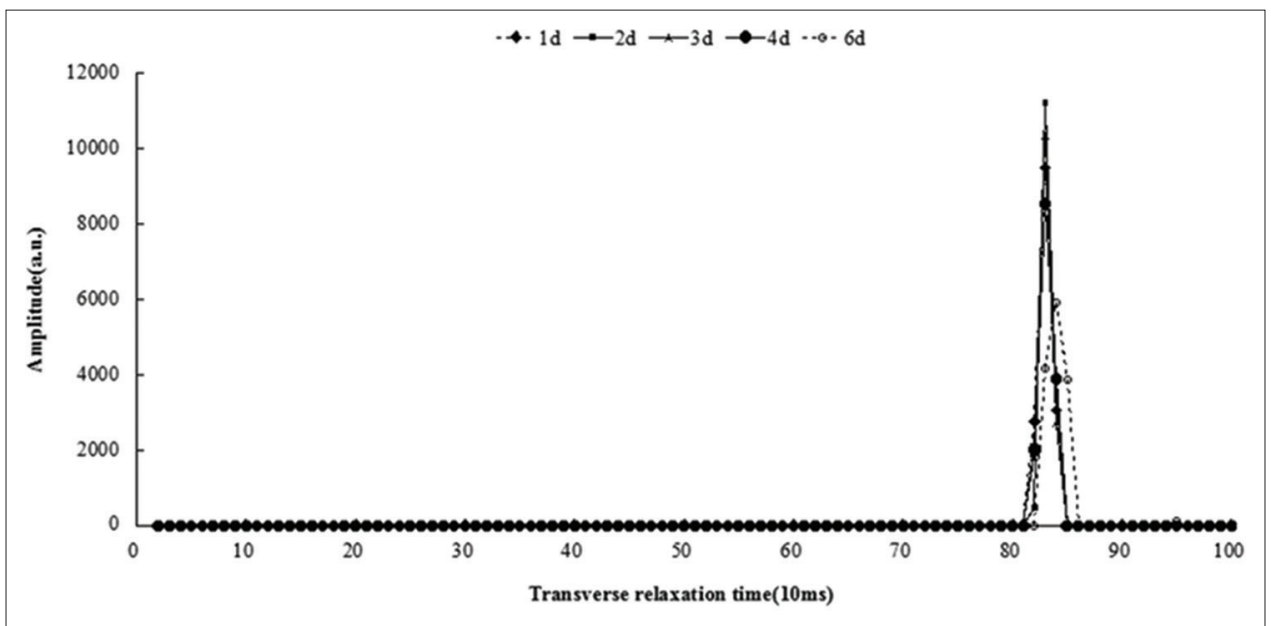

Fig 2. $T_{2}$ and $A_{2}$ of the yellow peach fruits at $25^{\circ} \mathrm{C}$. Amplitude: Free water content (a.u.: Arbitrary unit); transverse relaxation time: $T_{2}(10 \mathrm{~ms})$. 
temperature storage. The strength of $\mathrm{A}_{2}$ decreased with the storage time, suggesting a decline in the water content. Compared with storage at $25^{\circ} \mathrm{C}$, low temperature storage inhibited the loss of free water content, although it was still a serious problem after a long storage period.

\section{Relationships between ethylene production, firmness,} and LF-NMR at $25^{\circ} \mathrm{C}$ and $4{ }^{\circ} \mathrm{C}$

The ethylene production of the yellow peaches decreased over the first 2 days, did not change significantly on days 3-4, rose on days 5-6, followed by yet another decline after day 6 (Fig. 4). The firmness of the fruit declined continuously during the storage period at room temperature, with two different phases: I) a quick declining stage ( $0-4$ days' storage at room temperature) and II) a slow declining stage (5-10 days' storage at room temperature). Changes in the ethylene production corresponded well with $\mathrm{T}_{2}$ and $\mathrm{A}_{2}$ from LF-NMR. The ethylene release rate peaked after the critical time of the drop in firmness (firmness phase I), with significant changes in $\mathrm{T}_{2}$ and $\mathrm{A}_{2}$. Further research on the physiological and biochemical mechanisms of the fruit is required to assess whether ethylene release and water loss are due to fruit senescence and softening.

Ethylene production peaked on days 7 and 28 (Fig. 5); Compared with fruits stored at $25^{\circ} \mathrm{C}$, these peaks were significantly $(p<0.05)$ inhibited by low temperature. The two ethylene release peaks corresponded with $T_{2}$, with both $\mathrm{T}_{2}$ and water mobility declining significantly on days 5-11 ( $p \leq 0.05)$, and an even more dramatic decrease from days 11-21. Flesh firmness decreased significantly during days 0-14; by day 21, the firmness had declined to $10.44 \mathrm{~N}$, and during days $21-35$, the firmness stayed around 7.1-7.6 N. The strength of $\mathrm{A}_{2}$ decreased with the storage time, suggesting a reduction in the free water content. Low temperature inhibited ethylene production and water loss, which could have helped keep the fruit firm. The ethylene release rate peaked at a similar time (7-9 days) to $T_{2}$ and $\mathrm{A}_{2}$ for the low temperature treatment.

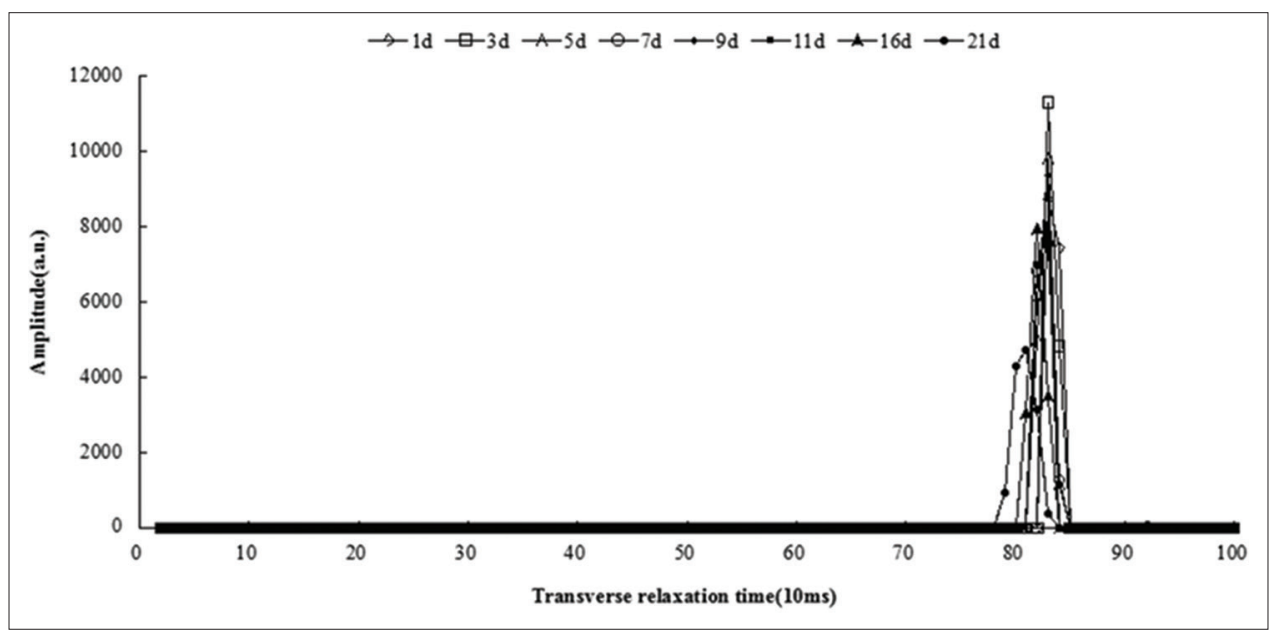

Fig 3. $T_{2}$ and $A_{2}$ of the yellow peach fruits at $4^{\circ} \mathrm{C}$. Amplitude: Free water content (a.u.:means arbitrary unit); Transverse relaxation time: $T_{2}(10 m s)$.

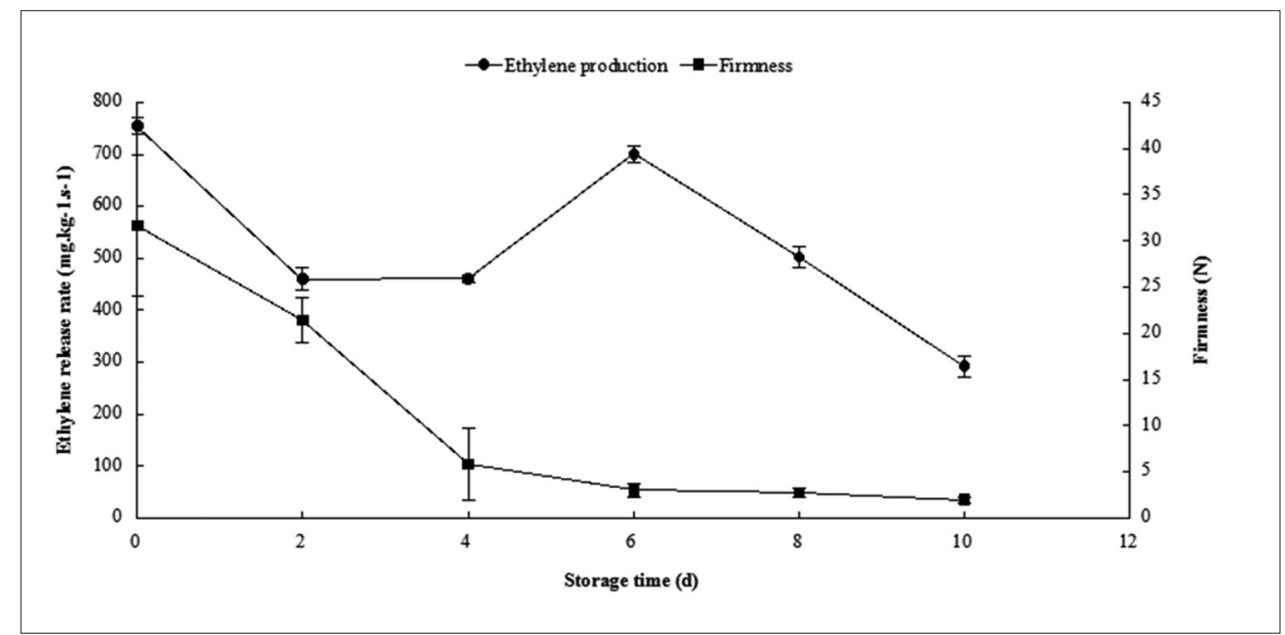

Fig 4. Ethylene production and firmness of yellow peach fruits stored at $25^{\circ} \mathrm{C}$. 


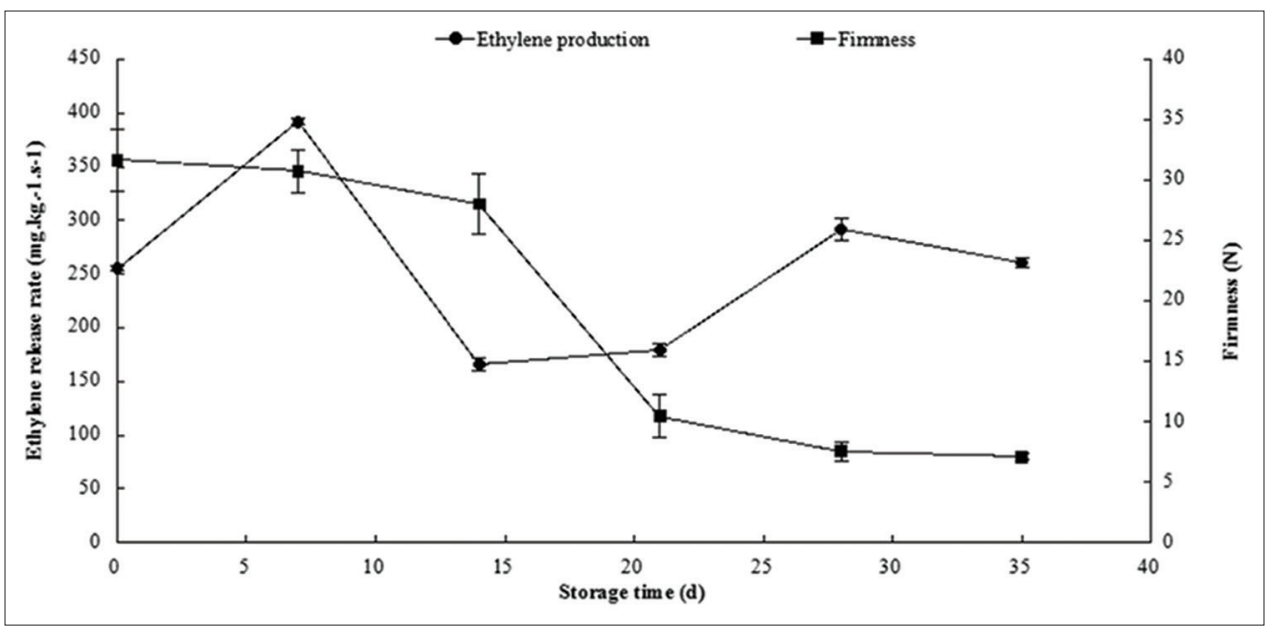

Fig 5. Ethylene production and firmness of yellow peach fruits stored at at $4^{\circ} \mathrm{C}$.

Table 3: Images of the different layers of yellow peach fruits from ${ }^{1} \mathrm{H}-\mathrm{MRI}$ at $25^{\circ} \mathrm{C}$

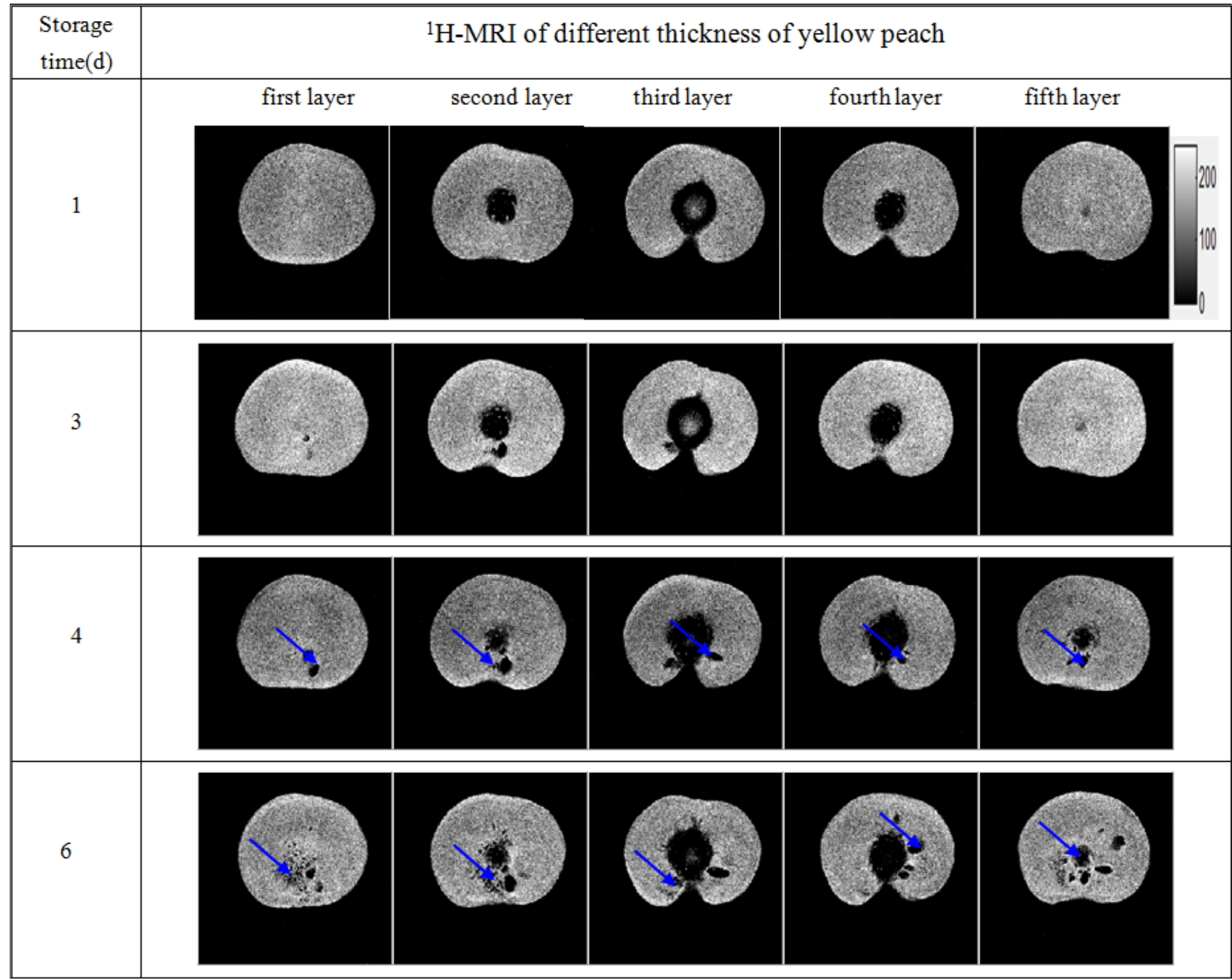

The blue arrow shows internal breakdown in the peach; ${ }^{1} \mathrm{H}-\mathrm{MRI}$, proton magnetic resonance imaging; the images of the first to the fifth layers were that the fruit were divided into five part nondestructively. The height of each layer was $15 \mathrm{~mm}$, and the total height of the fruit was $90 \mathrm{~mm}$ 
Changes in internal breakdown by ${ }^{1} \mathrm{H}-\mathrm{MRI}$ at $4^{\circ} \mathrm{C}$ and $25^{\circ} \mathrm{C}$

For the images testing by ${ }^{1} \mathrm{H}-\mathrm{MRI}$, the brighter the pixels, the stronger the proton $\mathrm{A}_{2}$ and the higher the water content. Table 3 and 5 shows the water distribution and internal breakdown of the flesh as assessed by ${ }^{1} \mathrm{H}-\mathrm{MRI}$ for the room temperature storage. On days 1-3, the pixels become brighter, suggesting an increase in the water

Table 4: Images of the different layers of yellow peach fruits as shown by ${ }^{1} \mathrm{H}-\mathrm{MRI}$ at $4^{\circ} \mathrm{C}$

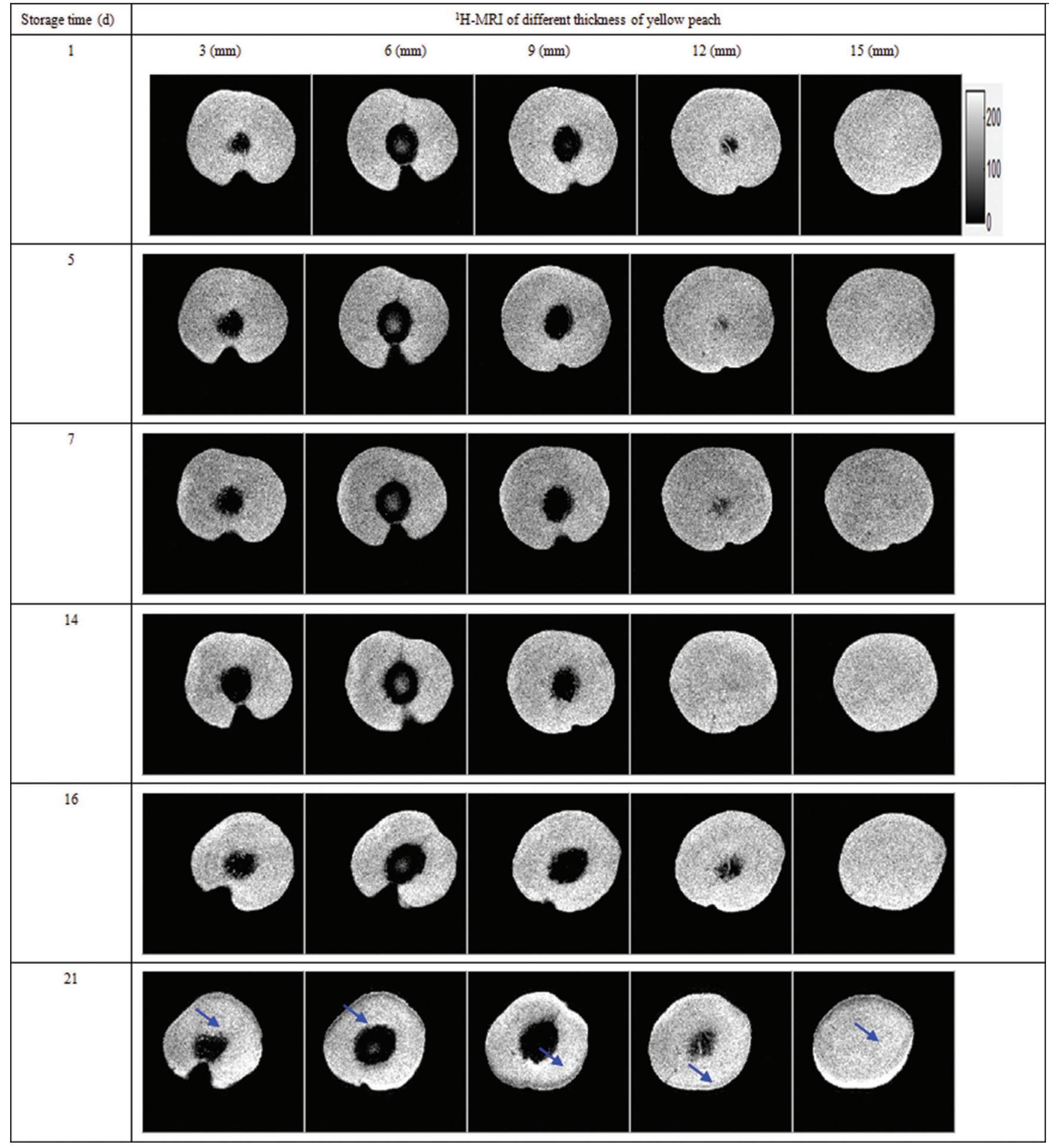

The blue arrow shows internal breakdown in the peach; ${ }^{1} \mathrm{H}-\mathrm{MRI}$ : Proton magnetic resonance image; images of the first to the fifth layer were that the fruit were divided into five part nondestructively. The height of one layer was $15 \mathrm{~mm}$, and the total height of the fruit was $90 \mathrm{~mm}$ 
Table 5: Changes in the appearance of yellow peach fruits stored at $25^{\circ} \mathrm{C}$

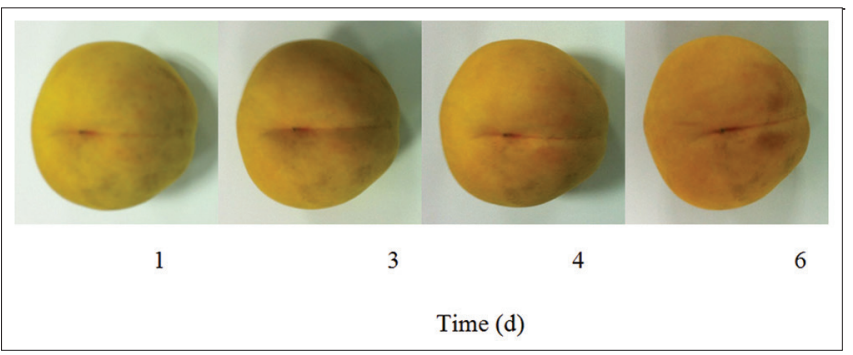

Table 6: Changes in the appearance of yellow peach fruits stored at $4^{\circ} \mathrm{C}$

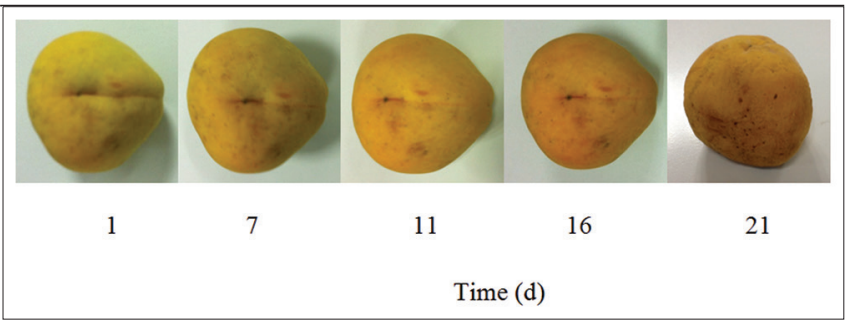

content, while on days $3-6$, the pixels of the different layers become darker, which might have been because the fluid from the ruptured cells displaced the air in the intercellular spaces, thus reducing the total interface area across the magnetic field gradients. The softening of the fruit had a similar tendency at warmer temperature; the water content increased with senescence during the early stages, but decreased during the later stages. This shows that flesh tissue collapsed between days 4 and 6 at room temperature $\left(25 \pm 2^{\circ} \mathrm{C}\right.$; $\left.\mathrm{RH} 75 \%-80 \%\right)$. Table 4 and 6 shows that the pixels of the different layers did not change as much at $4^{\circ} \mathrm{C}$ than $25^{\circ} \mathrm{C}$.

In the images (Table 3 and 6), cavities formed on day 3 in the second and third layers at room temperature, and on days 4-6, the cavity formation became more severe, with the pixels becoming brighter and the proton $\mathrm{A}_{2}$ increasing around the cavities. No cavities formed during the whole 21 days of storage for the low temperature samples.

\section{DISCUSSION}

NMR involves the interaction of the oscillating RF in the electromagnetic field with the experimental samples. LF-NMR is a novel technology that is faster and more accurate than the drying and solvent extraction method, and is suitable for the quantification of fat and water in organisms (Sorland et al., 2004). The present experiment revealed that yellow peach fruit had only one signal peak. The $T_{2}$ was found at $500-1000 \mathrm{~ms}$, and the free water was shown in the signal area of $\mathrm{A}_{2}$ (Shao and Li, 2013), which is earlier than that of potato (Liu and Wang, 2014), sweet corn (Shao and Li, 2013), and meat (Siciliano et al., 2013), but similar to that of apple (Mothibe et al., 2014).

$\mathrm{T}_{2}$ was affected by water content, the shorter the $\mathrm{T}_{2}$, the closer it was combined with water molecules and acrobiomolecular structure. On the contrary, it means that there are more free water content (Liu and Wang, 2014). The results indicate that the water mobility did not change; however, the signal strength decreased significantly over the storage time at room temperature, which suggests that the amount of free water decreased. On days 5-11, $\mathrm{T}_{2}$ decreased compared with that over the first 5 days, which suggests that the water mobility also decreased. In this study, low storage temperature inhibited the rate of water loss. Thus, yellow peach fruits should be consumed within 16 days when stored at low temperature $\left(4 \pm 1^{\circ} \mathrm{C}\right)$ and $\mathrm{RH}$ of $85 \%-90 \%$.

High adj- $R^{2}$ values were found for $T_{2}\left(R^{2}=0.95\right)$ and $\mathrm{A}_{2}\left(R^{2}=0.99\right)$ with water content at room temperature, as well as at low temperature $\left(R^{2}=0.93\right.$ and $R^{2}=0.97$, respectively), indicating a high degree of fit with the prediction equations. LF-NMR is a novel technology that could be an effective method to monitor and predict the water content of peaches during storage, instead of the invasive and time-consuming centrifugation method.

NMR technology can provide better images of the internal structure of intact fruits and vegetables, and thus, it is suitable for detecting internal defects and quality issues such as decay and maturity (Barreiro et al., 2000) (Barreiro et al., 2004). ${ }^{1} \mathrm{H}$-MRI technology can stimulate the RF-absorbing ability of fruits and vegetables as they have a multitude of proton-containing species (Cheng et al., 2014). Clark et al. used this method to investigate postharvest deterioration of "Fuji" apples (Liu and Wang, 2004), and observed the severity of the disorder. Its distribution within the fruit can be quantified by digitizing the affected and unaffected areas in each image in terms of deterioration. In the images from the ${ }^{1} \mathrm{H}$-MRI, the brighter the pixels, the stronger the proton $\mathrm{A}_{2}$ and the higher the water content. The present study showed that ${ }^{1} \mathrm{H}$-MRI could provide high-resolution images of the internal structure of intact fruits. The pixels became brighter on days $1-3$, showing an increase in the water content, while the pixels of the different layers became darker on days 3-6, which might have been caused by the fluid from the ruptured cells displacing the air in the intercellular spaces, and thus reducing the total interface area across the magnetic field gradients. The pixels in the different layers did not change as much during low temperature storage than during room temperature storage. The pixels became brighter and the proton $\mathrm{A}_{2}$ increased around the cavities, which is consistent with the results of McCarthy et al. (McCarthy et al., 1995), who found that 


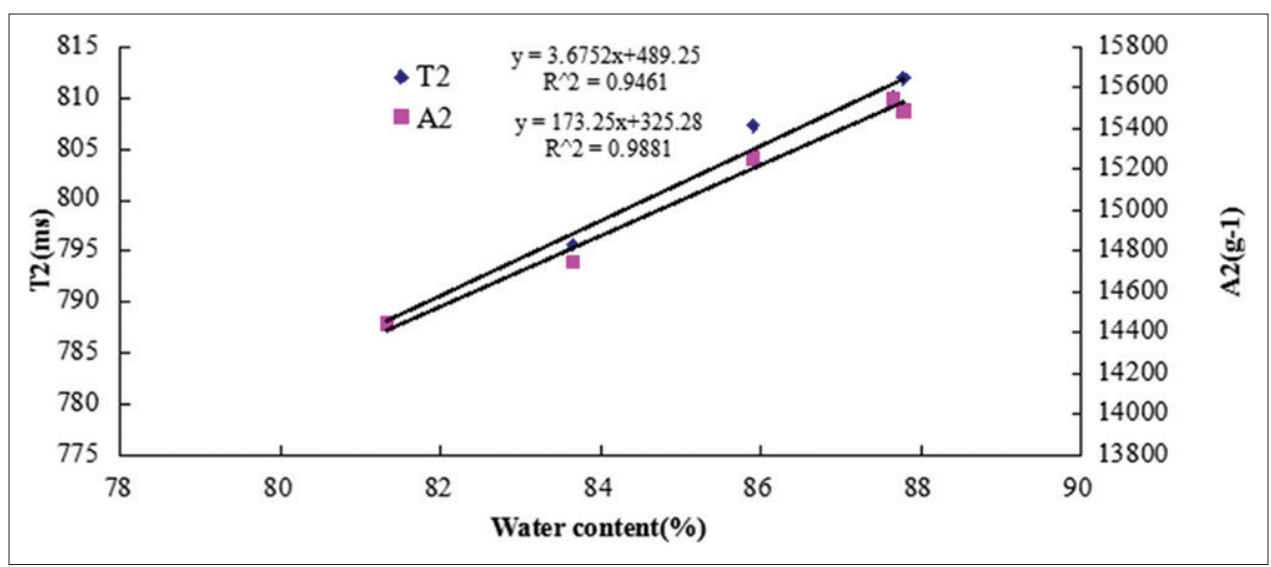

Fig 6. Linear regression equations showing the linear relationships between water content and $\mathrm{T}_{2}$ and $\mathrm{A}_{2}$ at $25^{\circ} \mathrm{C}$.

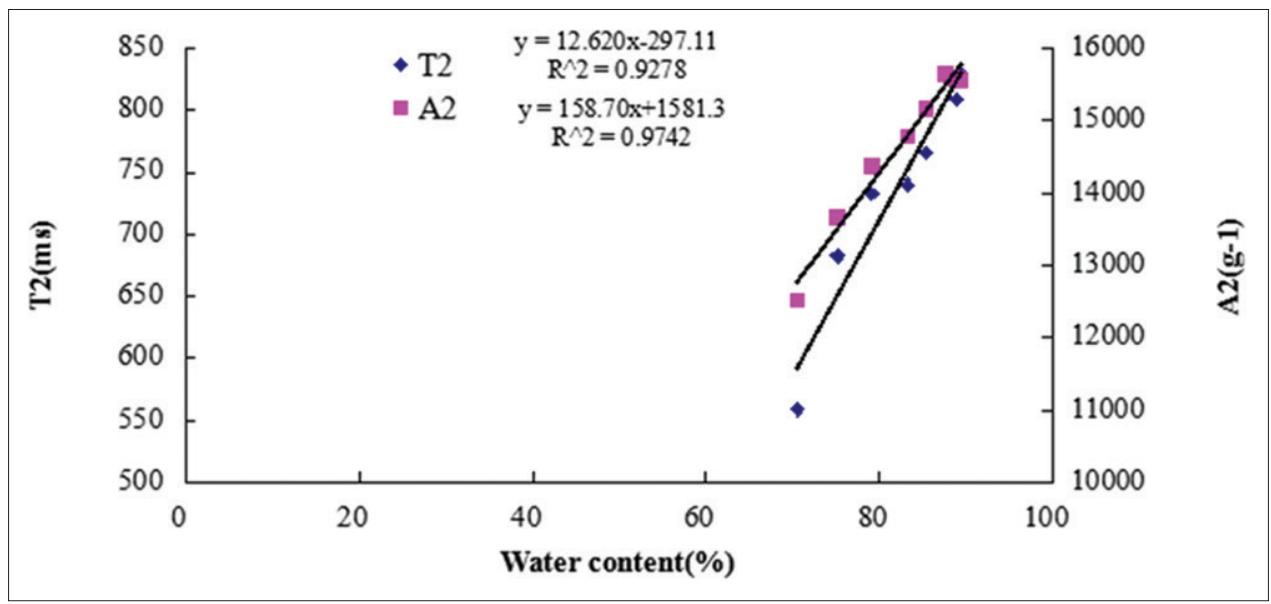

Fig 7. Linear regression equations showing the linear relationships between water content and $T_{2}$ and $A_{2}$ at $4^{\circ} \mathrm{C}$.

bruised tissue became brighter than intact tissues during storage due to changes in diamagnetic susceptibility.

The present study also shows that $A_{2}$ decreased in the images, with the tissue becoming brighter after low temperature storage. This may be because the $A_{2}$ near the stone became weaker than that near the peel as a result of water loss from the fruit stone. The pulp tissue near the stone tends to become woolly and bitter after prolonged storage, which is a negative sensory attribute combining the sensation of desegregated tissue with the sensation of a lack of crispness and juiciness, also known as mealiness in other fruits (Hill and Clark, 2014., 2003) (Panarese et al., 2012).

Peaches have a typical climacteric period, with a double respiration peak and an ethylene production peak; higher ethylene production is one of the important physiological reasons for water loss, decay, and unsuitability for storage, which are related to firmness and water content. Our study showed that changes in the ethylene release rate correspond to $\mathrm{T}_{2}$ and $\mathrm{A}_{2}$ as shown by LF-NMR during room temperature storage (4-6 days) and low temperature storage (16-21 days). The key time period for ethylene release, $\mathrm{T}_{2}$, and $\mathrm{A}_{2}$, is after the key period of fruit softening for room temperature storage and before the key period of softening for low temperature storage; further studies need to be performed to assess the relationships between these variables.

\section{CONCLUSIONS}

LF-MNR and ${ }^{1} \mathrm{H}-\mathrm{MRI}$ are effective technologies for the evaluation of the storage characteristics of yellow peach fruits. A signal peak was found after storage at $25^{\circ} \mathrm{C}$ and $4^{\circ} \mathrm{C}, \mathrm{T}_{2}$ ranged from $500 \mathrm{~ms}$ to $1000 \mathrm{~m}$ s. High adj- $R^{2}$ values were found for $\mathrm{T}_{2}$ and $\mathrm{A}_{2}$ with water content at $25^{\circ} \mathrm{C}$ $\left(R^{2}=0.95\right.$ and $R^{2}=0.99$, respectively) and at $4^{\circ} \mathrm{C}\left(R^{2}=0.93\right.$ and $R^{2}=0.97$, respectively), indicating a high degree of fit for the prediction equations (Figure 6 and 7). The key period of firmness corresponded to $\mathrm{T}_{2}, \mathrm{~A}_{2}$, and the images by LF-NMR for $25^{\circ} \mathrm{C}$ (4-6 days); for $4^{\circ} \mathrm{C}$ the key period (14-21 days) of firmness and water content corresponded to $\mathrm{T}_{2}$ and $\mathrm{A}_{2}$ (16-21 days). In this study, ${ }^{1} \mathrm{H}$-MRI provided 
high-resolution images of the internal structures of intact peaches. LF-NMR is a novel technology that could be an effective method for monitoring and predicting the water content of peaches during storage, and could be used instead of centrifugation.

\section{ACKNOWLEDGEMENTS}

This work was supported by China Agricultural Research System of Peach (CARS-31), The Youth Talent Development Project supported by Shanghai Municipal Agriculture Commission (NO 1-12,2015-2017) and Shanghai Research System of Peach (2121316,2014-2018).

\section{Author's contributions}

Z-W.Y and H-J.Z design the study. H-J.Z did the data analysis and wrote the paper. Z-F.Y corrected the article. M-S. S and J-H. D helped choose the varietal.

\section{REFERENCES}

Agudelo-laverde, L. M., C. Schebor and M. D. P. Buera. 2014. Proton mobility for the description of dynamic aspects of freeze-dried fruits. J. Food Eng. 125: 44-50.

Bakalova, R., N. Rumiana, M. Bilinan, A. Shuhei, Z. Severina, A. Zhivko, K. Ichio, T. Masaru, S. lana and I. Tsuneo. 2016. Passive and electro-assisted delivery of hydrogel nanoparticles in solid tumors, visualized by optical and magnetic resonance imaging in vivo. Anal. Bioanal. Chem. 408(3): 905-914.

Barreiro, P., A. M. Ruiz, C. Valero and R. F. J. Garcia. 2004. Fruit postharvest technology: Instrumental measurement of ripeness and quality. In: Quality Handling and Evaluation, Kluwer Academic Publishers, Dordrecht, Netherlands, Pp. 321-340.

Barreiro, P., C. Ortiz, A. M. Ruiz, C. J. Ruiz, V. M. E. Fernandez, I. Recsens and M. Asensio. 2000. Mealiness assessment in apples and peaches using MRI techniques. Magn. Reson. Imaging. 18(9): 1175-1181.

Bertram, H. C., S. Dønstrup, A. H. Karlsson and H. J. Andersen. 2002. Continuous distribution analysis of T2 relaxation in meat - An approach in the determination of water-holding capacity. Meat Sci. 60(3): 279-285.

Borompichaichartkul, C., G. Moran, G. Srzednicki and W. S. Price. 2005. Nuclear magnetic resonance (NMR) and magnetic resonance imaging (MRI) studies of corn at subzero temperatures. J. Food Eng. 69: 199-205.

Butz, P., C. Hofmann and B. Tauscher. 2005. Recent developments in noninvasive techniques for fresh fruit and vegetable internal quality analysis. J. Food Sci. 70(9): 131-141.

Chayaprasert, W. and R. Stroshine. 2005. Rapid sensing of internal browning in whole apples using a low-cost, low-field proton magnetic resonance sensor. Postharvest Biol. Technol. 36(3): 291-301.

Cheng, X. F., M. Zhang, B. Adhikari and M. D. N. Islam. 2014. Effect of power ultrasound and pulsed vacuum treatments on the dehydration kinetics, distribution, and status of water in osmotically dehydrated strawberry: A combined NMR and DSC study. Food Bioprocess Technol. 7(10): 2782-2792.

Farag, K. W., E. Duggan, D. J. Morgan, D. A. Cronin and J. G. Lyng.
2009. A comparison of conventional and radio frequency defrosting of lean beef meats: Effects on water binding characteristics. Meat Sci. 83(2): 278-284.

Gambhir, P. N., Y. J. Choi and M. J. McCarthy. 2004. Development of rapid and non-invasive nuclear magnetic resonance method for identifying freeze damaged citrus fruits. IFT Annual Meeting, Las Vegas, USA.

Gonzalez, M. E., D. M. Barrett, M. J. McCarthy, F. J. Vergeldt, E. Gerkema, A. M. Matser and A. S. H. Van. 2010. ${ }^{1} \mathrm{H}-\mathrm{NMR}$ study of the impact of high pressure and thermal processing on cell membrane integrity of onions. J. Food Sci. 75(7): 417-425.

Haiduc, A. M. and J. Van Duynhoven. 2005. Correlation of porous and functional properties of food materials by NMR relaxometry and multivariate analysis. Magn. Reson. Imaging. 23(2): 343-345.

Hernandz, S. N., B. P. Hils, P. Barreiro and N. Marigheto. 2007. An NMR study on internal browning in pears. Postharvest Biol. Technol. 44: 260-270.

Hill, B. P. and C. J. Clark. 2003. Quality assessment of horticultural products by NMR. Ann. Rep. NMR Spectrosc. 50: 75-120.

Krishna, K. P., A. K. Mohammad and K. Abhijit. 2015. Recent developments in applications of MRI techniques for foods and agricultural produce - An overview. J. Food Sci. Tech. 52(1): $1-26$.

Liu, R. X., X. H. Chen, M. Jiang and M. S. Dong. 2014. Water distribution in tofu and application of $\mathrm{T}_{2}$ relaxation measurements in determination of tofu's water-holding capacity. J. Agric. Food Chem. 62(34): 8594-8601.

Marigheto, N., A. Val, K. Wright and B. Hills. 2004. A combined NMR and microstructural study of the effect of high-pressure processing on strawberries. Appl. Magn. Reson. 26(4): 521-531.

McCarthy, M. J., B. Zion, P. Chen, S. Ablett, A. H. Darke and P. J. Lillford. 1995. Diamagnetic susceptibility change in apple tissue after bruising. J. Sci. Food Agric. 67: 13-20.

Mortensen, M., A. K. Thybo, H. C. Bertram, H. J. Andersen and S. B. Eegelsens. 2005. Cooking effects on water distribution in potatoes using nuclear magnetic resonance relaxation. J. Agric. Food Chem. 53(15): 5976-5981.

Mothibe, K. J., M. Zhang, A. S. Mujumdar, Y. C. Wang and X. F. Cheng. 2014. Effects of ultrasound and microwave pretreatments of apple before spouted bed drying on rate of dehydration and physical properties. Drying Tech. 32(15): 1848-1856.

Ogasa, Y., U. Mayumi, M. Yasuhiro, H. Y. Naoko, F. Kenichi and Kenji. 2016. Cutting stems before relaxing xylem tension induces artefacts in vitis coignetiae, as evidenced by magnetic resonance imaging. Plant Cell Environ. 39(2): 329-337.

Panarese, V., L. Laghi, A. Pisi, U. Tylewicz, M. D. Rosa and P. Rocculi. 2012. Effect of osmotic dehydration on actinidia deliciosa kiwifruit: A combined NMR and ultrastructural study. Food Chem. 132(4): 1706-1712.

Reid, L. M., C. P. O'donell and G. Downey. 2006. Recent technological advances for the determination of food authenticity. Trends Food Sci. Tech. 17(7): 344-353.

Ruiz-cabrera, M. A., P. Gou, L. Foucat, J. P. Renou and J. D. Daudin. 2004. Water transfer analysis in pork meat supported by NMR imaging. Meat Sci. 67(1): 169-178.

Shao, X. L. and Y. F. Li. 2013. Application of low-field NMR to analyze water characteristics and predict unfrozen water in blanched sweet corn. Food Bioprocess Technol. 6(6): 1593-1599.

Sequi, P., M. T. Dellabate and M. Valentini. 2007. Identification of cherry tomatoes growth origin by means of magnetic resonance imaging. J. Sci. Food Agric. 87: 127-132.

Siciliano, C., E. Belsito, R. Demarco, M. L. Digoia, A. Leggio and 
A. Liguori. 2013. Quantitative determination of fatty acid chain composition in pork meat products by high resolution ${ }^{1} \mathrm{H}-\mathrm{NMR}$ spectroscopy. Food Chem. 136(2): 546-554.

Sorland, G. H., P. M. Larsen, F. Lunby, A. P. Rudi and U. T. Guiheneuf.
2004. Determination of total fat and moisture content in meat using low field NMR. Meat Sci. 66(3): 543-550.

Xiao, Z., Z. Wang and T. Liu. 2004. Application of multi-exponential inversion method to NMR measurements. Petro Sci. 1: 19-22. 